DOI: 10.17707/AgricultForest.63.1.16

\author{
Nina MORAVČÍKOVÁ, \\ Radovan KASARDA, Ondrej KADLEČÍK ${ }^{I}$
}

\title{
THE DEGREE OF GENETIC ADMIXTURE WITHIN SPECIES FROM GENUS CERVUS
}

\begin{abstract}
SUMMARY
The aim of present study is to estimate the level of admixture within species originating from genus Cervus (family Cervidae) that can reflect not only their phylogeny origin, but mainly the impact of introgression and hybridization in Red deer population inhabit the forest area of Slovakia. It was happened over the last few centuries. Recently, the introduction and hybridization by non-native species is considered as the major risk of diversity loss within autochthonous Red deer populations in area of Central Europe. The genomic data were obtained from in total 61 animals (species A. axis, D. dama, C. elaphus, C. Nippon, C. canadensis) based on applying the cross-species SNP genotyping (Illumina BovineSNP50 BeadChip). The quality control of genotyping data has been performed to eliminate any SNPs with genotyping errors (loci with $>10 \%$ missing genotypes), less informative markers (MAF<0.01) and markers deviating from Hardy-Weinberg equilibrium limit of 0.0001 . From totally $43.21 \%$ of successfully genotyped markers up to 843 were informative for subsequent estimation. As expected the presence of admixed individuals was found within Red deer and Wapiti populations, but the signal of cross-species admixture was low. The membership probabilities of individuals were higher than $90 \%$ within each of analysed cervid group. Our study showed that the Slovak Red deer population can provide valuable gene pool within Central European deer populations in respect to the management of genetic resources conservation strategies.
\end{abstract}

Keywords: deer, diversity, cross-species genotyping, hybridization.

\section{INTRODUCTION}

Worldwide, human-mediated translocations increase the rates of introgression from non-native into native taxa. In addition, range shifts, especially in temperate areas, also involve increased population admixture. Potential negative effects include introgression of non-native gene copies, loss of local adaptations and breaking up of co-adapted gene complexes (Haanes et al., 2013). Introgression that induces transfer of genes from one species to another by

\footnotetext{
${ }^{1}$ Nina Moravčíková (corresponding author: nina.moravcikova@uniag.sk), Radovan Kasarda, Ondrej Kadlečík Department of Animal Genetics and Breeding biology, Slovak University of Agriculture in Nitra, Nitra, SLOVAKIA

Paper presented at the $7^{\text {th }}$ International Scientific Agricultural Symposium "AGROSYM 2016".

Notes: The authors declare that they have no conflicts of interest. Authorship Form signed online.
} 
repeated backcrossing and hybridization that results in admixture of parental genes from 2 different species are a major threat to biodiversity as they can cause the loss of fitness through outbreeding depression and in some cases, even extinction (Malcolm, 2015). In addition, ongoing hybridization can cause the native population to be replaced by one genetically and phenotypically resembling the non-native form in some traits, while individuals containing nonnative genetic material might be morphologically indistinguishable from those containing an intact native genome (Biedrzyck aet al., 2012).

To determine the outcome of introgression and admixture from non-native into native taxa, long-term monitoring is suggested. Non-indigenous introduction have been common in game management, especially in red deer (Cervus elaphus) that is one of the most widespread and important game species in Europe (Haanes et al., 2013). The populations of Red deer have been subjected to a variety of anthropogenic interventions (historic or relatively recent) that have potentially affected the genetic structure of local populations (KrojerováProkešová et al., 2015). Currently, the conservation status of native Red deer populations are threatened with extinction in some parts of Central Europe. The major cause is the hybridisation with an Asian species of the Japanese Sika deer (Cervus nippon) and North America Wapiti (Cervus canadensis) (Macháček et al., 2014). The Sika deer have been introduced to many countries and the hybridisation with native Red deer population has been demonstrated in British Isles (Malcolm, 2015), Czech Republic (Bartoš et al., 1982; Macháček et al., 2014), Poland (Biedrzycka et al., 2012) or Germany (Herzog et al., 2016). However, in addition to local hybridization with sika three major conservation issues exist: threatened genetic lineages, and blurring of natural genetic structuring through translocations and reintroductions; selective hunting; and reduced effective population sizes due to habitat fragmentation (Zachos and Hartl, 2011). For long-term conservation and development purposes, it therefore appears compulsory to manage Red deer wildlife to maintain both species survival and within species genetic diversity.

The aim of present study was to assess the level of admixture within species originating from five species from tribe Cervini and especially genus Cervus (family Cervidae) that can reflect not only their phylogeny origin, but mainly the impact of introgression and hybridization in Red deer population inhabit the forest area of Slovakia.

\section{MATERIALS AND METHODS}

To assess the degree of genetic admixture within five species from tribe Cervini the dataset consisted of genotyping data from in total of 61 individuals: 29 Red deer (Cervus elaphus - Cela), 8 Sika deer (Cervus nippon - Cnip), 8 Wapiti (Cervus canadensis - Ccan), 8 Fallow deer (Dama dama - Ddam), and 8 Axis deer (Axis axis - Aaxi) has been used. The final dataset was created by merging of new data from 29 free living and farmed red deer inhabit the forest area in southwestern part of Slovakia that were genotyped by the Illumina 
BovineSNP50 v2 BeadChip and previously published data of 32 cervids obtained by using the BovineSNP50 v1 BeadChip (Illumina, Inc. San Diego, USA) as described Decker et al. (2009). Overall 36,451SNPs common to both analysed datasets were retained in reduced panel of loci. The subsequent quality control of genotyping data has been conducted to exclude any SNPs with call rate lower than $90 \%$, minor allele frequency lower than 0.01 and HWE limit of $1 \times 10^{-4}$ using PLINK (Purcell et al., 2007).

After applying quality control, 843loci across autosomes were used to analyse the state of genetic diversity within each of analysed species based on indices derived from allelic frequency; observed $\left(\mathrm{H}_{\mathrm{o}}\right)$ and expected $\left(\mathrm{H}_{\mathrm{e}}\right)$ heterozygosities and Wright's $F_{\text {IS }}$ index using Genalex v6.1 software (Peakall and Smouse, 2012). The degree of genetic differentiation among cervid species was assessed based on Nei's genetic distances using R package StAMPP (Pembleton et al., 2013)and visualised using R package ape (Paradis et al., 2004).

To examine population genetic structure the discriminant analysis of principal components (DAPC) adopted in R package Adegenet (Jombart and Ahmed, 2011) was applied on genotyping data. The optimum numbers of clusters was determined by running a K-means algorithm that use Bayesian Information Criterion (BIC). Overall $10^{9}$ iterations of the model were used to search for convergence and obtainment of the likelihood associated with each value of $\mathrm{K}$ between 1 and 30. The DAPC analysis was also used to assign individuals and to obtain the membership probability which present the overall genetic background of an individual.

The population structure without prior information of individual's origin was also evaluated based on Bayesian clustering approach proposed by Pritchard et al. (2000) implemented in Structure v2.3 software. The analysis was carried out based on a model with admixture and correlated allele frequencies using burn-in period of 100,000 followed by 1,000,000 MCMC replications. Runs for each selected value of $K(1-10)$ were repeated ten times. The optimal value of clusters was selected based on evaluation of the log probability of delta $K(\Delta K)$ according to Evanno et al. (2005).

\section{RESULTS AND DISCUSSION}

Of the total 36,451 loci retained in reduced panel, 15,754 autosomal SNPs have been successfully genotyped in at least $90 \%$ of individuals with call rate at level of $61.04 \%$. This marked decrease of genotyping call rate in comparison to species from family Bovidae was caused mainly by the fact that the applied genotyping array has been primarily designed to Bos Taurus. In relation to this Miller et al. (2012) found that the cross-species application of such array can result in $1.5 \%$ decrease of call rate per each million year divergence between species.

Despite that the $43.21 \%$ of loci from the bovine array could be genotyped, most of them were monomorphic and only $2.31 \%$ of SNPs showed polymorphism. The number of identified informative loci was comparable to 
results presented by $\mathrm{Wu}$ et al. (2013) that similarly used cross-species genotyping to evolutionary related water buffalo. Relative higher proportion of polymorphic SNPs at level of 5\% found Hayes and Latch (2012) and Kharzinova et al.(2015) within the species Odocoileus virginianus and Rangifer tarandus, respectively. However, the results of cross-species genotyping have to be described with cation mainly due to the differences between cervid and bovid genome that resulted in favour of conserved genomic regions that still retain polymorphisms ancestral to the divergence between Cervidae and Bovidae families(Haynes and Latch, 2012).

The level of observed heterozygosity ranged from $0.012 \pm 0.001$ (Axis deer) to $0.13 \pm 0.07$ (Red deer). The species from genus Cervus (Red deer, Wapiti and Sika) showed higher level of expected heterozygosity in comparison to genera Axis (Axis deer) and Dama (Fallow deer). The prevalence of homozygotes in particular groups and on the level of whole population confirmed also the value of Wright's $F_{\text {IS }}(0.294 \pm 0.008)$ and $F_{\text {IT }}$ indexes $(0.821 \pm 0.012)$. The results showed lower degree of genetic variability within Slovak red deer population than presented Maršálková et al. (2014) using microsatellite markers. In addition, the value of $F_{I S}$ index can signalize the potential risk of inbreeding increase accompanied by the decrease of genetic diversity within population.

The value of $\mathrm{F}_{\mathrm{ST}}$ index $(0.913 \pm 0.071)$ indicated that most of the genetic variation was conserved within separate species that clearly showed also subsequently estimated genetic relationships based on Nei's distances. The average genetic distances ranged from 0.05 (Red deer and Wapiti) to 0.697 (Axis and Fallow deer). The observed distances suggested the distribution of individuals into the three maingenetic clusters. The groups were formed by individuals from genera Cervus, Axis and Dama (Figure 1A).

The DAPC approach similarly confirmed a strong distinction among species in relation to their phylogenetic origin. The division of individuals in to the clusters produced by BIC analysis showed that the inferred clusters corresponded to the initial groups with optimal value of $\mathrm{K}=5$. The first and second discriminant function clearly demonstrated the closest genetic affinity between the species from genus Cervus and division of individuals in to the three clusters(Figure 1B and 1C). Similarly, the Bayesian assignment analysis and the method proposed by Evanno et al. (2005) favoured a model with three clusters. Based on this it can be stated that the panel of 843 selected polymorphic loci applied to analysis of population structure significantly reflected the evolution and phylogeny of analysed species and is prospective for future management of Red deer population in order to maintain genetic diversity.

The membership probability outputs suggested that the allele frequencies varied continuously across the regions composed from genera Cervus, Dama and Axis (Figure 1E). The evidence of admixture has been found only based on DAPC analysis in genus Cervus. The presence of admixed individuals was identified between the species Red deer and Wapiti (Figure 1D). 
A)

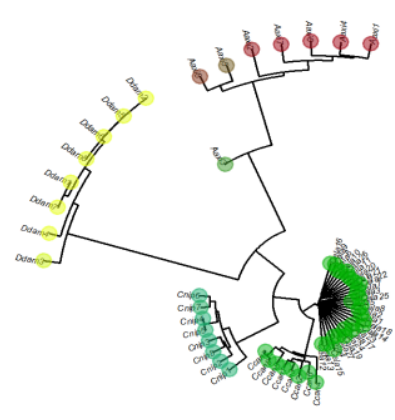

B)

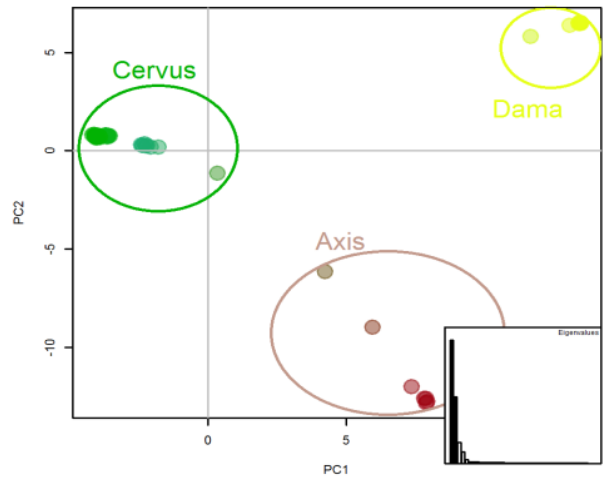

C)

Aaxi

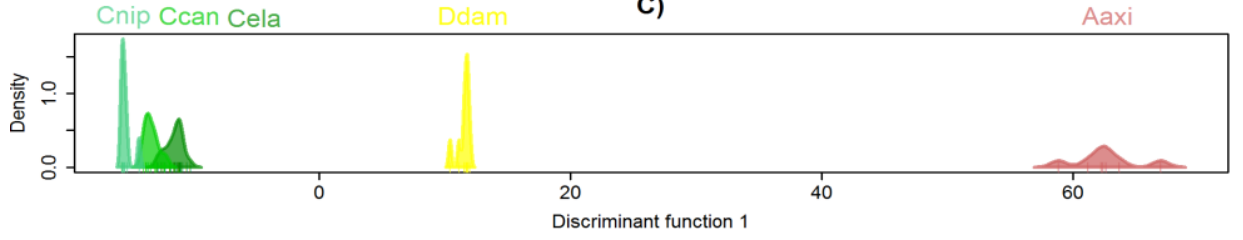

D)

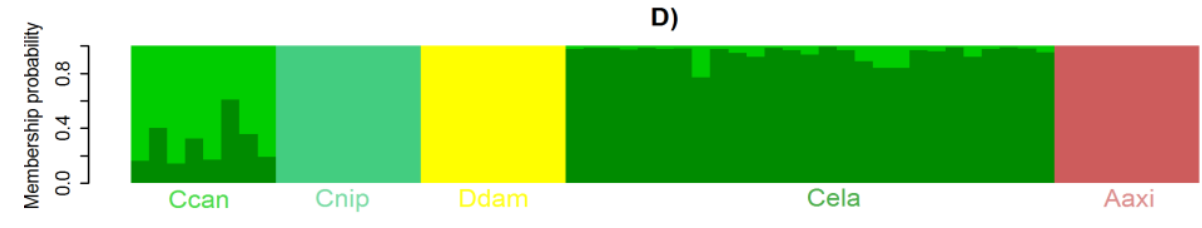

E)

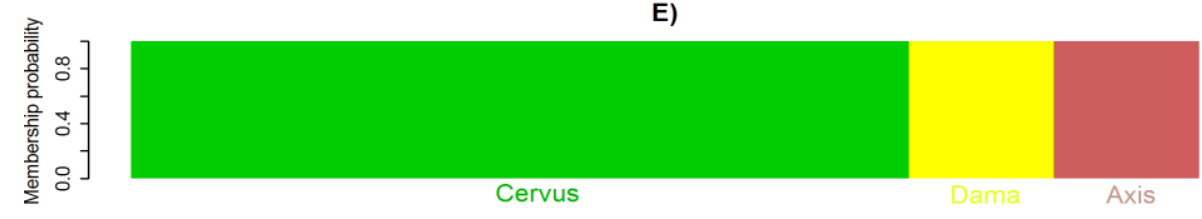

Figure 1. The phylogenetic tree representing genetic relationship based on Nei's distances (A), the structure of population based on PCA analysis (B), genetic clusters determined using first discriminant function (C), and membership probability resulting from DAPC analysis (D) and Bayesian clustering approach implemented in STRUCTURE (E)

This happened probably as a consequence of the introduction of red deer with various origin (Cervus Elaphus Hippelaphus, C. Elaphus Sibiricus, and C. Elaphus Canadensis) into the Slovak population during the $19^{\text {th }}$ century (Apollonio et al., 2010). Despite that the population of Red deer inhabits the Slovakia is often described as the subspecies Cervus Elaphus Hippelaphus, but in practice is rather a mongrel mixture of genotypes (Bališ et al., 1980). Any level of admixture between the Slovak Red deer and Sika, which could be caused by 
its introduction in to the neighbouring countries (for example Czech Republic), was not confirmed. In practical use this can be beneficial not only for the improvement of deer farming in Slovakia, but also for other local populations mainly in respect to the conservation of its genetic resources, sustainable management and prevention of genetic diversity loss.

\section{CONCLUSIONS}

Our study showed that the gene pool of Slovak Red deer population is not affected by introduction of Sika as non-native species into the local population inhabits neighbouring countries. The membership probability outputs suggested that the allele frequencies varied continuously across the three main regions composed from genera Cervus, Dama and Axis, while the presence of admixed individuals has been identified only within genus Cervus and species Red deer and Wapiti as a consequence of deerfarming history in Slovakia. Based on the fact that many areas of Central Europe are threatened by risk of loss of autochthonous populations due to the hybridisation with Sika, the Slovak Red deer population can be regarded as valuable gene poolmainly in respect to the conservation strategies of its genetic resources.

\section{ACKNOWLEDGMENT}

This work has been supported by the Slovak Research and Development Agency (Contracts No. APVV-14-0054 and SK-AT-2015-0016). Part of the work was done during the stay of the authors at BOKU Vienna, supported by the Austrian Agency for International Cooperation in Education and Research (OeAD-GmbH, project SK 07/2016). We would like to thank for cooperation the Xcell Slovakia Breeding Services s.r.o. and namely Ing. J. Pokorádi, Phd., who provided the biological samples of Red deer.

\section{REFERENCES}

Apollonio, M., Andersen, R., Putman, R. (2010). European Ungulates and Their Management in the 21st Century, Cambridge University Press, Cambridge, United Kingdom.

Bališ, M. (1980). Jelenia zver, Príroda, Bratislava, Slovakia.

Bartoš, L., Žirovnický, J. (1982). Hybridization between red deer and sika deer. II. Phenotype analysis, Zoologischer Anzeiger, 207, 271 - 287.

Biedrzycka, A., Solarz, W., Okarma, H. (2012). Hybridization between native and introduced species of deer in Eastern Europe, Journal of Mammalogy, 93, 1331 - 1341.

Decker, J. E., Pires, J. C., Conant, G. C., McKay, S. D., Heaton, M. P., Chen, K., Cooper, A., Vilkki, J., Seabury, C. M., Caetano, A. R., Johnson, G. S., Brenneman, R. A., Hanotte, O., Eggert, L. S., Wiener, P., Kim, J. J., Kim, K. S., Sonstegard, T. S., Van Tassell, C. P., Neibergs, H. L., McEwan, J. C., Brauning, R., Coutinho, L. L., Babar, M. E., Wilson, G. A., McClure, M. C., Rolf, M. M., Kim, J., Schnabel, R. D., Taylor, J. F. (2009). Resolving the evolution of extant and extinct ruminants with high-throughput phylogenomics, Proc Natl AcadSci U S A, 106, 18644 - 18649.

Evanno, G., Regnaut, S., Goudet, J. (2005). Detecting the number of clusters of individuals using the software STRUCTURE: a simulation study, Molecular Ecology, 14, 2611 2620 . 
Haanes, H., Rosvold, J., Røed, K. H. (2013). Non-indigenous introgression into the Norwegian red deer population, Conservation Genetics, 14, 237 - 242.

Haynes, G. D., Latch, E. K. (2012). Identification of novel single nucleotide polymorphisms (SNPs) in deer (Odocoileus spp.) using the BovineSNP50 BeadChip, PLoS One, 7:e36536.

Herzog, S., Gehle, T. (2016). Hybridization in the Genus Cervus: Evidence for Hybridization between Red and Sika Deer in Germany, Academic Journal of Applied Sciences Research, 1, 7 - 9.

Jombart, T., Ahmed, I. (2011). Adegenet 1.3-1: new tools for the analysis of genome-wide SNP data, Bioinformatics, 1, 3070 - 3071.

Kharzinova, V. R., Sermyagin, A. A., Gladyr, E. A., Okhlopkov, I. M., Brem, G., Zinovieva, N. A. (2015). A Study of Applicability of SNP Chips Developed for Bovine and Ovine Species to Whole-Genome Analysis of Reindeer Rangifer tarandus, Journal of Heredity, 106, 758 - 761.

Krojerová-Prokešová, J., Barančeková, M., Koubek, P. (2015). Admixture of Eastern and Western European Red Deer Lineages as a Result of Postglacial Recolonization of the Czech Republic (Central Europe),Journal of Heredity, 106(4), 375 - 385.

Macháček, Z., Dvořák, S., Ježek, M., Zahradník, D. (2014). Impact of interspecific relations between native red deer (Cervuselaphus) and introduced sika deer (Cervusnippon) on their rutting season in the Doupovskéhory Mts, Journal of forest science, 60(7), 272 280.

Malcolm, S. (2015). An Ethical Assessment on the Management of Introduced Sika Deer (Cervus nippon) in Scotland; With Particular Reference to Hybridisation with Native Red Deer (C. elaphus), Journal of Student Research, 4(2), 13 - 27.

Maršálková, L., Židek, R., Pokoradi, J., Golian, J., Belej, L. (2014). Genetic diversity and relatedness among seven red deer (Cervuselaphus) populations, Potravinárstvo, 8, 15 19.

Miller, J. M., Kijas, J. W., Heaton, M. P., McEwan, J. C., Coltman, D. W. (2012). Consistent divergence times and allele sharing measured from cross-species application of SNP chips developed for three domestic species, Molecular Ecology Resources, 12, 1145 1150 .

Paradis, E., Claude, J., Strimmer, K. (2004). APE: analyses of phylogenetics and evolution in R language, Bioinformatics, 20, 289 - 290.

Peakall, R., Smouse, P. E. (2012). GenAlEx 6.5: genetic analysis in Excel. Population genetic software for teaching and research-an update, Bioinformatics, 28, 2537 - 2539.

Pembleton, L. W., Cogan, N. O. I., Forster, J. W. (2013). StAMPP: an R package for calculation of genetic differentiation and structure of mixed-ploidy level populations, Molecular Ecology Resources, 13, 946 - 952.

Pritchard, J. K., Stephens, M., Donnelly, P. (2000). Inference of population structure using multilocus genotype data, Genetics portions from molecular data, Molecular Biology and Evolution, 15, 1298 - 1311.

Purcell, S., Neale, B., Todd-Brown, K., Thomas, L., Ferreira, M. A., Bender, D., Maller, J., Skalp, P., De Bakker, P. L., Daly, M. J., Sham, P. C. (2007). PLINK: a tool set for whole genome association and population-based linkage analysis, Am J Hum Genet, $81,559-575$.

Wu, J. J., Song, L. J., Wu, F. J., Liang, X. W., Yang, B. Z., Wathes, D. C., Pollott, G. E., Cheng, Z., Shide, S., Liu, Q. Y., Yang, L. G., Zhang, S. J. (2013). Investigation of transferability of BovineSNP50 BeadChip from cattle to water buffalo for genomewide association study, Molecular Biology Reports, 40, 743 - 750.

Zachos, F. E., Hartl, G. B. (2011). Phylogeography, population genetics and conservation of the European red deer Cervuselaphus. Mammal Review, 41, 138 - 150. 